\title{
Maternal and foetal outcome in patients of gestational diabetes mellitus
}

\author{
Priyanka* \\ Department of Obstetrics and Gynecology, Katihar Medical College, Katihar, Bihar, India
}

Received: 09 July 2018

Accepted: 02 August 2018

\section{*Correspondence:}

Dr. Priyanka,

E-mail: drsaifomar@gmail.com

Copyright: $\odot$ the author(s), publisher and licensee Medip Academy. This is an open-access article distributed under the terms of the Creative Commons Attribution Non-Commercial License, which permits unrestricted non-commercial use, distribution, and reproduction in any medium, provided the original work is properly cited.

\section{ABSTRACT}

Background: Indian women have high Prevalence of diabetes and their relative risk of developing gestational diabetes mellitus (GDM) is 11.3 times compared to white women. The metabolic adaptations during pregnancy are designed to maintain a continuous availability of substrate to accommodate the fetal growth. Aims of present study were the antenatal screening of Gestational diabetes mellitus and its pregnancy outcome.

Methods: The present study is a type of prospective study in this study 6000 pregnant women were randomly selected for screening irrespective of gestational age and any of the risk factor. All consenting pregnant, who came for first absolute neutrophil count in outpatient department, pregnant women of any parity, and singleton pregnancies were included.

Results: Out of 6000 women screened 200 were found positive for GDM. The study indicated that GDM was 3.33\%. The incidence of GDM was found to be more in women $>25$ years age. Fetal outcome was satisfactory in well controlled GDM, only 7 babies were macrosomic, 13 intrauterine death and 5 still birth, 10 babies required NICU admission for hypoglycemia, respiratory distress syndrome, septicemia.

Conclusions: Fetal outcome was satisfactory in well controlled GDM. There was no neonatal mortality. Hence, GDM and its complications are preventable.

Keywords: Gestational diabetes mellitus, Maternal risk factor, Pregnancy

\section{INTRODUCTION}

Gestational diabetes mellitus.GDM) is a state of glucose intolerance with the onset or first recognition occurring during pregnancy. ${ }^{1,2}$ It shows the most common metabolic complications of pregnancy, and fetal mortality and morbidity. ${ }^{1}$ Therefore, early diagnosis of GDM is necessary to reduce maternal and fetal morbidity and to help to prevent or delay the onset of type 2 diabetes. ${ }^{3}$ GDM is the most common and serious metabolic complication which put mother and baby at risk of potential complications. The GDM is a distinct clinical entity deserving early recognition, treatment and research. It is estimated that $2-3 \%$ of pregnancies are complicated by diabetes and $90 \%$ of these cases represent women with GDM. ${ }^{4,5}$ Its frequency is rising in United State and occurs in $1-14 \%$ of all pregnancies. ${ }^{4}$ The carbohydrate intolerance is usually a temporary condition induced by the metabolic stress of pregnancy and treated by diet control alone or by insulin therapy. This abnormality in glucose metabolism may or may not normalized to normal after delivery. Gestational diabetes recurs in about $60 \%$ of subsequent pregnancies and $40 \%$ of Gestational diabetics will develop non-insulin dependent diabetes mellitus within 15 years after delivery and this was the background for the original diagnostic criteria. ${ }^{6,7}$ Normoglycaemia in the peri-conceptual period and first trimester is essential to reduce the increase incidence of congenital malformations, which threaten the organogenesis. ${ }^{4,8}$ Early diagnosis and prompt 
treatment decreases the incidence of congenital malformations. ${ }^{9}$ If GDM is not properly treated the risk of adverse maternal (pre-eclampsia, pregnancy induced hypertension, emergency caesarean section, assisted delivery) and neonatal (macrosomia, still birth, birth trauma, shoulder dystocia) outcome increases. The incidence of gestational diabetes mellitus is between $0.15-15 \%$, which corresponds to the prevalence of type 2 diabetes and impaired glucose tolerance in a given country. The prevalence of gestational diabetes mellitus is $0.15 \%$ in New Castle, UK, $1.8 \%$ in Nairobi, $1.9 \%$ in Riyadh, 2-3\% in North America, 5.4\% in Bahrain, 2.5$7.5 \%$ in Bostol. ${ }^{4,10-12}$ Indian women have high prevalence of diabetes and their relative risk of developing GDM is 11.3 times compared to white women. ${ }^{13}$ Hoc Diabetes Reporting Group noted markedly different rates of diabetes and IGT in different populations, from as low as $<1 \%$ to $>10 \%$. In some of the populations, more than half the cases of diabetes were undiagnosed prior to the survey. IGT was mostly overlooked in routine clinical practice. Thus, a substantial proportion of abnormal glucose tolerance in pregnancy goes undetected without screening. ${ }^{14}$ Therefore, the present study was the antenatal screening of Gestational diabetes mellitus and its pregnancy outcome.

\section{METHODS}

The present study was carried out on the patients attending the outpatient department of Katihar Medical College, Katihar during the period of study from January 2017 to December 2018. All pregnant women attending the Gynaecology and Obstetrics outpatient department (OPD) of Katihar medical college were included irrespective of their gestational age at their first visit, as per the above inclusion and exclusion criteria. Before data collection, women were given cleared description of the purpose of the study as well as screening process and informed written signed consent was taken. Women were subjected to random / fasting blood glucose testing. The venous blood sample was collected in a sodium fluoride container. If the value is $\geq 126 \mathrm{mg} \%$ (fasting) or $\geq 200$ $\mathrm{mg} \%$ (random) then they were diagnosed as pre-existing diabetes and excluded from the study. Other patients were undergone 2 hour $75 \mathrm{gm}$ glucose (oral glucose tolerance test-OGTT) test. They were given $75 \mathrm{gm}$ glucose dissolved in $250 \mathrm{ml}$ water, to be taken within 5 minutes. After two hours venous blood sample was collected. If 2 hours values $<140 \mathrm{mg} / \mathrm{dl}$ then no GDM, $>140$ then considered as GDM. No further OGTT was performed and consider only the plasma values. Those who had diagnosed GDM, they were be followed for maternal and fetal outcome like PIH, caesarian delivery, macrosomia and neonatal complications etc. All consenting pregnant, who came for first absolute neutrophil count in OPD, pregnant women of any parity and singleton pregnancies were included. Pre-gestational diabetes, chronic disease with cardiac or hepatic or respiratory disease, taking drug that alter glucose metabolism and patients who refused to participate were excluded in study.

\section{Statistical analysis}

All the relevant data is collected as per proforma and tabulated in Microsoft Excel and was analysed using statistical software and $\mathrm{p}$ value $<0.05$, it was considered as significant. Analysis of data was done using appropriate statistical software like SPSS.

\section{RESULTS}

Out of 6000 women screened 200 were found positive for GDM. In which 20 women was not come for follow up and only 180 women were further examined and continued till delivery. In this study, incidence of pregnancy with GDM was $3.33 \%$ (Table 1).

Table 1: Incidence of pregnancy with GDM.

\begin{tabular}{|lll|}
\hline $\begin{array}{l}\text { Total pregnant } \\
\text { women }\end{array}$ & $\begin{array}{l}\text { Pregnant women } \\
\text { with GDM }\end{array}$ & $\begin{array}{l}\text { Percentage of } \\
\text { GDM }\end{array}$ \\
\hline 6000 & 200 & 3.33 \\
\hline
\end{tabular}

Out of 200 cases positive for GDM, majority of cases $70(35 \%)$ were belonged in age group of 26-30 years and $60(30 \%)$ in age group of $>30$ years (Figure 1$)$.

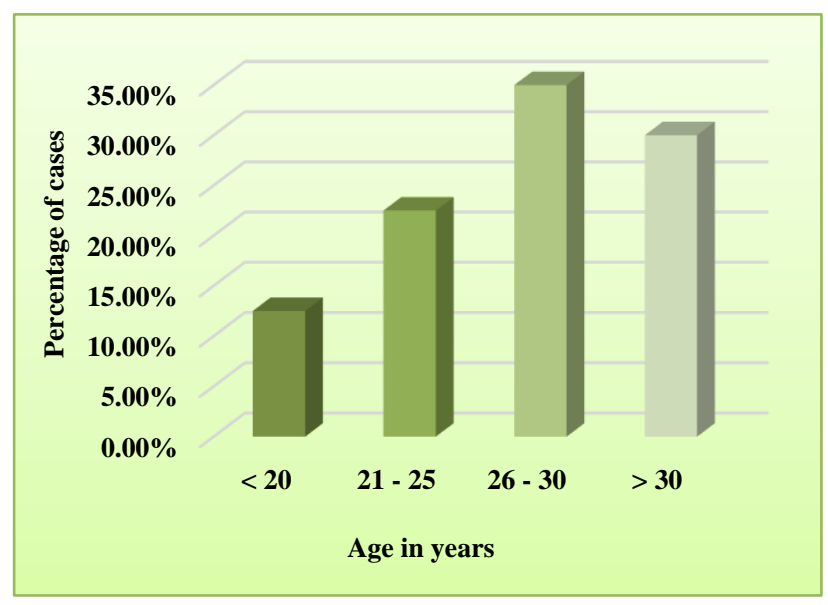

Figure 1: Correlation of incidence of GDM in different age group.

In this study, pregnant women having GDM at age > 30 years and $13(6.5 \%)$ primi grada as well as $46(23 \%)$ multigravida (Table 2).

Table 2: Distribution of pregnant women having GDM age $>30$ years.

\begin{tabular}{|lcl|}
\hline Gravida & No. of patients & Percentage \\
\hline Primigravida & 13 & 6.5 \\
\hline Multigravida & 46 & 23 \\
\hline Total & 59 & 29.5 \\
\hline
\end{tabular}


In this study, authors found that majority of cases $140(70 \%)$ were gestational age 13-29 weeks (Table 3).

Table 3: Gestational age at diagnosis of GDM.

\begin{tabular}{|lll|}
\hline Gestational age & No. of patients & Percentage \\
\hline$<12$ weeks & 15 & 7.5 \\
\hline $13-29$ weeks & 140 & 70 \\
\hline$>30$ weeks & 45 & 22.5 \\
\hline Total & 200 & 100 \\
\hline
\end{tabular}

The total patients were followed till delivery. In most of the patients delivery occurred after 35 weeks where survival of fetus $100 \%$. About $13 \%$ pregnancy terminated before 34 weeks. $5 \%$ of pregnancies were carried after 40 weeks that was postdated as shown Figure 2.

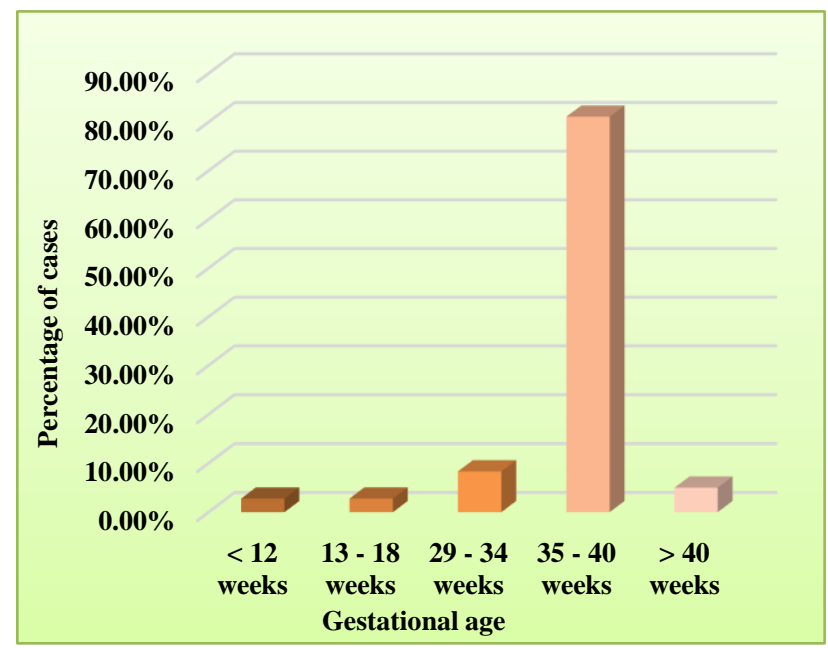

Figure 2: Continuation of pregnancy till delivery in women with GDM taken treatment.

Most of the delivery 132(73.33\%) was vaginal, only (35) $19.44 \%$ were terminated by lower segment cesarian section (LSCS). In the treated patient $118(65.55 \%)$ babies were of average birth weight $2.5-3.0 \mathrm{~kg}$, and only $7(3.88 \%)$ babies were macrosomic. As shown in Table 4 , all the GDM treated patients $5(2.77 \%)$ women had abortion. Intrauterine death was occurred in $13(7.22 \%)$ women, still birth in $5(2.77 \%)$ babies. Live birth rate was higher $87.22 \%$.

Table 4: Pregnancy outcome in patient of GDM with treatment.

\begin{tabular}{|ll|l|}
\hline & No. of babies & Percentage \\
\hline Abortion & 5 & 2.77 \\
\hline Intrauterine death & 13 & 7.22 \\
\hline Still birth & 5 & 2.77 \\
\hline Live birth & 157 & 87.22 \\
\hline Total & 180 & 100 \\
\hline
\end{tabular}

Most of the patients $162(90 \%)$ were benefited by medical nutrition therapy and exercise. Only $10 \%$ were required insulin (Table 5).
Table 5: Response of treatment provided in GDM patient.

\begin{tabular}{|lll|}
\hline Treatment & No. of patients & Percentage \\
\hline $\begin{array}{l}\text { Medical nutrition } \\
\text { therapy + exercise }\end{array}$ & 162 & 90 \\
\hline Insulin & 18 & 10 \\
\hline Total & 180 & 100 \\
\hline
\end{tabular}

As shown in Figure 3, major complication was developed during pregnancy with positive GDM were 16 (37.20\%) preterm labour, $13(30.23 \%)$ intra uterine death, 5 $(11.62 \%)$ polyhydramnios, $4(9.30 \%)$ pregnancy-induced hypertension and $3(6.97 \%)$ vaginal candidiasis.

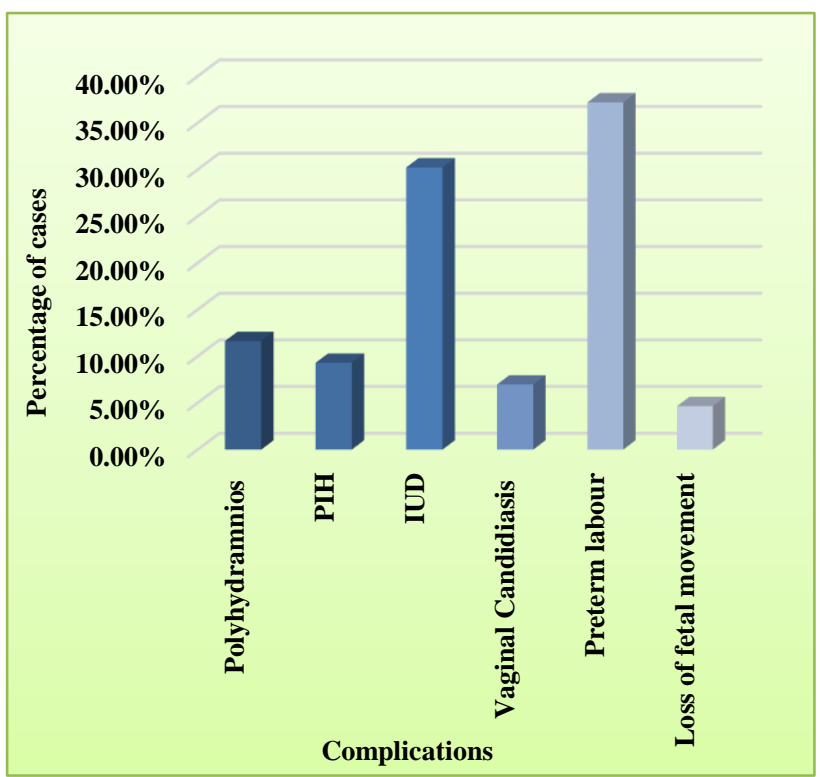

Figure 3: Complications that developed during pregnancy in GDM treated patients.

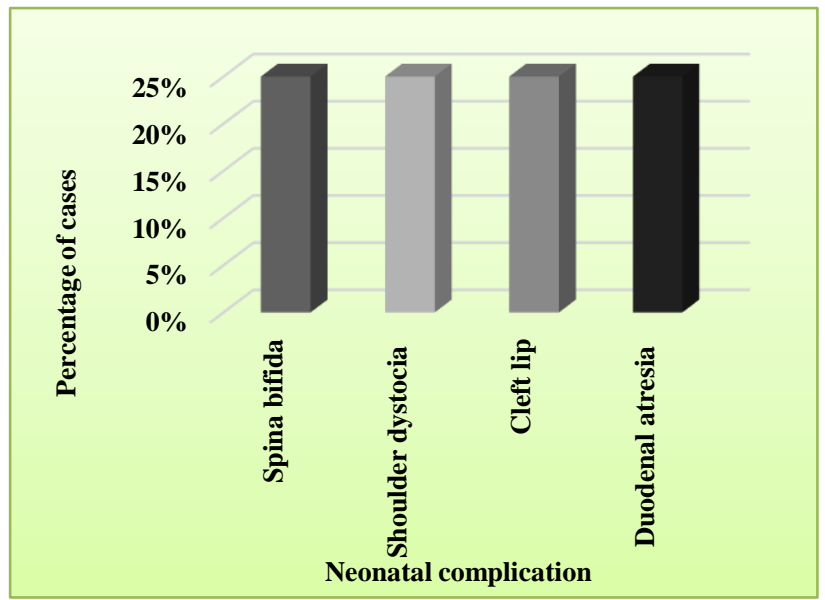

Figure 4: Neonatal complications that developed in GDM treated patients.

Among 180 cases, 8(4.44\%) cases were developed neonatal complication. Furthermore, out of 8 cases, 
$2(25 \%)$ cases were spina bifida, shoulder dystocia, cleft lip and duodenal atresia (Figure 4).

Among 200 patient's positive for GDM, 18 (9\%) patients were having bad obstetrical history like recurrent pregnancy loss as represent in Table 6.

\section{Table 6: Prevalence of $\mathrm{BOH}$ in women positive for GDM.}

\begin{tabular}{|lll|}
\hline NOH & No. of patients & Percentage \\
\hline Total & 18 & 09 \\
\hline
\end{tabular}

As presented in Figure 5, total 200 patients positive for GDM about $10(5 \%)$ patients were having positive risk factor (family history).

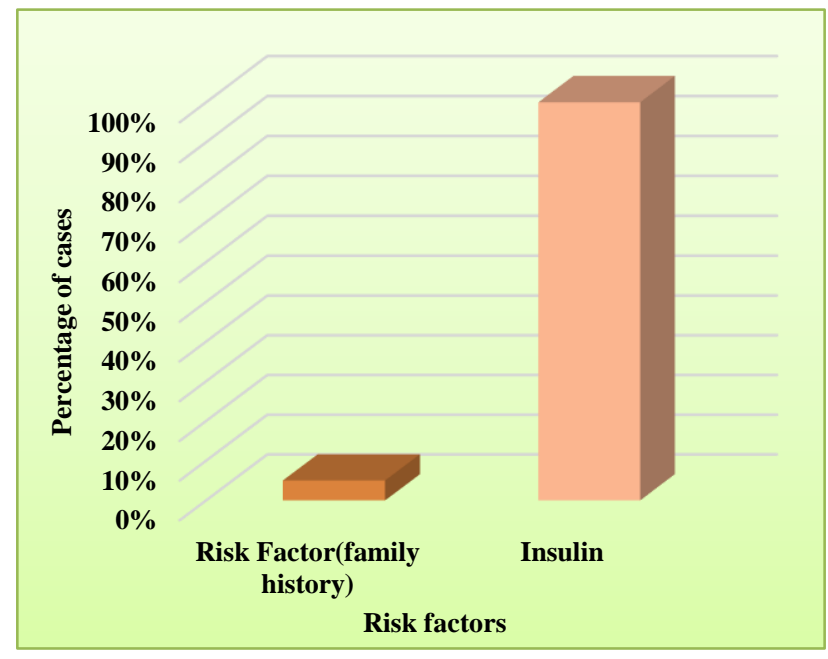

Figure 5: Prevalence of positive risk factors of pregnancy with GDM.

\section{DISCUSSION}

GDM refers to any degree of glucose intolerance with onset or first recognition during pregnancy. ${ }^{15}$ Evidences showed that GDM poses a threat to adverse maternal and perinatal outcomes as a result of maternal hyperglycemia. Women with a history of GDM have a high risk of progression to type 2 diabetes mellitus. ${ }^{13}$ Pregnancy induces progressive changes in maternal carbohydrate metabolism. ${ }^{16}$ While the pregnancy advances insulin resistance and diabetogenic stress due to placental hormones necessitate compensatory increase in insulin secretion. When this compensation is inadequate, GDM develops. ${ }^{16}$ Indian women have high prevalence of diabetes and their relative risk of developing GDM is 11.3 times compared to white women. ${ }^{17}$ The incidence rate of pregnancy with GDM was $3.33 \%$ in present study. Present findings were similar the findings of Bartha JL, et al in their study incidence of gestational diabetes is $3-5 \%$ of all live births which is now increasing due to the rise in obesity and gestational age. ${ }^{18}$ However, age groups of cases were 20 to greater than 30 years. Majority of cases of pregnant women with GDM $70(35 \%)$ were belonged to age group of 26-30 years. 60 (30\%) cases with GDM was belonged to age group of $>30$ years. Similar findings were found by Dudhwadkar AR et al. ${ }^{15}$ There were concluded that maximum patients $(56 \%)$ were clustered in the age group of 26-30 years and $30 \%$ of patients were over 30 years of age. A study in Jammu region also stated that compared with women of normal OGTT, women with GDM were older. ${ }^{16}$ Thus GDM affects older women more than younger ones, in concert with the pathophysiologies of the disease. In the present study, $6.5 \%$ patients were primigravida while $23 \%$ patients were multigravida at age over 30 years. Out of 200 cases $43.5 \%$ cases were multigravida. In accordance with Rajput et al. shows that higher parity would have a higher rate of GDM. ${ }^{17}$ On the other hand, out of 200 cases the majority of pregnant women with GDM.70\%) had gestational age 13-29 weeks. Among 200 cases, 180 pregnant women with gestational diabetes mellitus were continued treatment till delivery of babies. Authors were seen that out of 180 treated cases, majority of cases $81.11 \%$ had gestational age $35-40$ weeks. Study conducted by Szymańska $M$ et al concluded that diagnosis of GDM during the recommended period (between 24 and 28 weeks of pregnancy) may decrease the prevalence of large for gestational age (comparing to later diagnostics). ${ }^{19}$ In present study, most of the delivery $132(73.33 \%)$ was vaginal, only $19.44 \%$ were terminated by LSCS.20 Furthermore, Dudhwadkar AR et al were found $46 \%$ patients were delivered vaginally. ${ }^{15}$ Although, $30 \%$ of vaginal deliveries were induced at 38 weeks of gestation while $70 \%$ went into spontaneous labour. Over $2 \%$ deliveries were vacuum assisted. $52 \%$ patients underwent LSCS. According to Kale et al the incidence of LSCS in patients with GDM was found to be $60 \% .^{21}$ Qadir et al reported $41.8 \%$ caesarean section rate. ${ }^{4}$ The present study shown that, major indication of LSCS was Cephalo-pelvic disproportion (36.11\%), fetal distress $(27.77 \%)$ and obstructed labour (13.88\%) Authentic studies on caesarean section rate in India could not be found. A study on the rates of caesarean section in the medical college and hospital GMERS, Sola, Ahmedabad stated a rate of $25.1 \% .^{22}$ There has been a steady increase in the rates of cesarean section in both developed and developing countries although there is a wide variation in caesarean rates between the two owing to limited resources in the developing nations. The caesarean section rate in Africa was $6.2 \%$ of which most common indication was obstructed labor $(31 \%)$ in contrast to cephalopelvic disproportion in present study. ${ }^{23}$ In United Kingdom, the caesarean rate was $24.1 \%$ of all live births. $^{24}$ No standard classification system exists for indications of $\mathrm{CS}^{25,26}$ In present study, majority of newborns $(65.55 \%)$ were birth weight $2.5-3.0 \mathrm{~kg}$. Only $03.88 \%$ cases were macrosomia. The most commonly used definition of macrosomia is a birth weight equal to or exceeding $4000 \mathrm{~g}$. The incidence is however far lower than other many published studies $(>30 \%)$ conducted on GDM. ${ }^{27,28}$ Control of diabetes in most of the pregnancies either by diet or insulin might reduce the incidence of 
macrosomia in GDM. Studies proclaim that prophylactic insulin therapy will reduce the incidence of macrosomia among infants of GDM. ${ }^{29}$ This is also in conformity with a previous study done in BIRDEM hospital, Bangladesh which included both pre GDM and GDM cases. One recent investigation in India has explored that tight control of GDM causes large for gestational age of the baby instead of reducing the birth weight. ${ }^{30}$ The present study was seen live birth $(87.22 \%)$, intrauterine death (7.22\%), still birth and abortion (2.77\%). Complication that was developed in this study was preterm labour (37.20\%), IUD $(30.23 \%)$, polyhydramnios (11.62\%), PIH $(9.30 \%)$, vaginal candidiasis $(6.97 \%)$, and loss of fetal movement $(4.65 \%)$.

The study by Bhat et al cites a $14.7 \%$ incidence of polyhydramnios versus $2.7 \%$ in controls. ${ }^{31}$ Macrosomia and perinatal mortality are considered as adverse pregnancy outcomes in patients with GDM. Over $30.23 \%$ babies were intrauterine deaths in the present study contrast to $6 \%$ intrauterine deaths reported in the study by Saxena et al. ${ }^{32}$ The Indian consensus is that a new born weighing $>3.5 \mathrm{~kg}$ should be considered as macrosomia. In present study, $3.88 \%$ babies were macrosomic at birth which is high compared to other Indian studies were the incidence was $28 \%$. In a study by Mahalakshmi MM et al in South India, $77.5 \%$ of babies were term live births while $19 \%$ were preterm live birth. ${ }^{33}$ Preterm births in present study were attributed to premature preterm rupture of membranes, preterm labour and early induction in cases of severe preeclampsia. In present study, majority of cases $(90 \%)$ were treated with medical nutrition and exercise, only $10 \%$ cases were given insulin. A study conducted by Jovanovic-Peterson L concluded that approximately $15 \%$ of women with GDM require insulin therapy. ${ }^{34}$ This finding was nearly similar with findings of present study. In present study, only 10 babies were developed neonatal complications in GDM treated patients. Out of these 10 babies $25 \%$ babies were developed spina bifida, shoulder dystocia, cleft lip and duodenal atresia. Infants of diabetic mothers have an increased risk of developing congenital malformations. Qadir et al study found that severe and major malformation occurred in $15.5 \%$ infants while this rate was $2 \%$ in present study. ${ }^{4}$ Present study result correlates well with other studies $3.3 \% 81,3.85 \% 82$ and $4 \% 83$. Low rate in present study could be due to this fact as $82 \%$ women developed diabetes in late second or third trimester. Dudhwadkar AR et al were found that $26.52 \%$ patients underwent LSCS. $^{15}$ Also, 34\% $(n=17)$ were elective while $18 \% \quad(n=9)$ were emergency LSCS of which 7 were for fetal distress and two patients had intrapartum placental abruption. Intrapartum, shoulder dystocia occurred in two patients (4\%). Postpartum haemorrhage occurred in $3.6 \%$ patients. Post-partum haemorrhage due to atonic uterus was seen in two cases with polyhydramnios. Family history of diabetes has a strong correlation with occurrence of GDM. In this present study, out of 200 pregnant women with GDM, only $18(09 \%)$ women were bad obstetric history like recurrent pregnancy loss. $10(5 \%)$ patients were having positive family history of GDM. Naylor et al found glucose intolerance in $14.5 \%$ of women who had adverse obstetric outcomes. ${ }^{35}$ Dudhwadkar AR et al was found that positive family history as a risk factor in $20 \%$ patients in their study. ${ }^{15}$ In the study conducted in UK by Nanda et al positive family history was found in $23.9 \%$ patients. $^{36}$ Women with a history of GDM as well as offspring exposed to maternal diabetes in utero should be a major area of focus for preventive medicine. Preventive measures against type 2 diabetes mellitus should start during intrauterine period and continue throughout life from early childhood. Since the only expenditure involved is a simple screening blood test, it is recommended that all patients be universally screened for GDM. A short-term intensive care gives a long term pay off in the primary prevention of impaired glucose tolerance, diabetes and obesity in the offspring, as preventive medicine starts before birth. The maternal health and fetal outcome depend upon the care by the committed team of diabetologists, obstetricians and neonatologists.

\section{CONCLUSION}

The incidence of GDM was found to be more in women greater than 25 years age. Fetal outcome was satisfactory in well controlled GDM. There was no neonatal mortality. Hence GDM and its complications are preventable, so proper measures should be taken to reduce its incidence and effect. Therefore, universal screening should be provided to all pregnant women irrespective of presence or absence of risk factor. So according to this study, antenatal screening for GDM should be done universally in all pregnant women irrespective of last meal. So that women positive for GDM should be screened out.

\section{Funding: No funding sources \\ Conflict of interest: None declared}

Ethical approval: The study was approved by the Institutional Ethics Committee

\section{REFERENCES}

1. Metzger BE, Buchanan TA, Coustan DR, De Leiva A, Dunger DB, Hadden DR, et al. Summary and recommendations of the fifth international workshopconference on gestational diabetes mellitus. Diabetes Care. 2007;30(Supplement 2):S251-60.

2. Jovanovic L, Pettitt DJ. Gestational diabetes mellitus. Jama. 2001;286(20):2516-8.

3. Kim C, Newton KM, Knopp RH. Gestational diabetes and the incidence of type 2 diabetes: a systematic review. Diabetes Care. 2002;25(10):1862-8.

4. Qadir SY, Yasmin T, Fatima I. Maternal and foetal outcome in gestational diabetes. J Ayub Med Coll Abbottabad. 2012;24(3-4):17-20.

5. Crowe SM, Mastrobattista JM, Monga M. Oral glucose tolerance test and the preparatory diet. Am J Obstet Gynecol. 2000;182(5):1052-4. 
6. O'Sullivan JB. Diabetes mellitus after GDM. Diabetes. 1991;40(Supplement 2):131-5.

7. O'Sullivan JB. Criteria for the oral glucose tolerance test in pregnancy. Diabetes. 1964;13:278-85.

8. Riskin-Mashiah S, Younes G, Damti A, Auslander R. First trimester fasting hyperglycemia and adverse pregnancy outcomes. Diabetes Care. 2009.

9. Shaukat A, Arain T, Abid S, Mahmud R. Criteria for detecting gestational diabetes mellitus. National Diabetes Data Group Versus World Health Organization. J Coll Physicians Surg Pak. 1999;9(5):211-4.

10. Ray JG, O'brien TE, Chan WS. Preconception care and the risk of congenital anomalies in the offspring of women with diabetes mellitus: a meta-analysis. QJM: Monthly J Assoc Phys. 2001;94(8):435-44.

11. Al-Shawaf T, Ariel A, Mogiiraby S. Gestational diabetes and impaired glucose tolerance of pregnancy in Riyadh. BJOG: An Int J Obstet Gynaecol. 1988;95(1):84-90.

12. Hadden D. Geographic, ethnic, and racial variations in the incidence of gestational diabetes mellitus. Diabetes. 1985;34(Supplement 2):8-12.

13. Dornhorst A, Paterson C, Nicholls J, Wadsworth J, Chiu D, Elkeles R, et al. High prevalence of gestational diabetes in women from ethnic minority groups. Diabetic Medicine. 1992;9(9):820-5.

14. Ad W. Hoc diabetes reporting group. Diabetes and impaired glucose tolerance in women aged 20-39 years. World Health Stat. 1992;45:321-7.

15. Dudhwadkar AR, Fonseca MN. Maternal and fetal outcome in gestational diabetes mellitus. Int J Reprod Contracept Obstet Gynecol. 2016;5(10):3317-21.

16. Wahi P, Dogra V, Jandial K, Bhagat R, Gupta R, Gupta $\mathrm{S}$, et al. Prevalence of gestational diabetes mellitus (GDM) and its outcomes in Jammu region. J Assoc Phys India. 2011;59(4):227-30.

17. Rajput R, Yadav Y, Nanda S, Rajput M. Prevalence of gestational diabetes mellitus \& associated risk factors at a tertiary care hospital in Haryana. Indian J Med Res. 2013;137(4):728.

18. Bartha JL, Martinez-Del-Fresno P, Comino-Delgado R. Gestational diabetes mellitus diagnosed during early pregnancy. Am J Obstet Gynecol. 2000;182(2):346-50.

19. Szymańska M, Bomba-Opoń D, Celińska A, Wielgoś M. Diagnostic of gestational diabetes mellitus and the prevalence of LGA (Large for Gestational Age). Ginekologia Polska. 2008;79(3):177-81.

20. Dornhorst A, Nicholls J, Welch A, Ali K, Chan S, Beard R. Correcting for ethnicity when defining large for gestational age infants in diabetic pregnancies. Diabetic Med. 1996;13(3):226-31.

21. Kale S, Yajnik C, Kulkarni S, Meenakumari K, Joglekar A, Khorsand N, et al. High risk of diabetes and metabolic syndrome in Indian women with gestational diabetes mellitus. Diabetic Med. 2004;21(11):1257-8.

22. Nikhil A. Analysis of Trends in LSCS Rate and Indications of LSCS-A Study in a Medical College Hospital GMERS, Sola, Ahmedabad. Int J Pharm BioSci. $2015 ; 2(1)$.
23. Chu K, Cortier H, Maldonado F, Mashant T, Ford N, Trelles M. Cesarean section rates and indications in sub-Saharan Africa: a multi-country study from Medecins sans Frontieres. PloS One. 2012;7(9):e44484.

24. Nichols M, Townsend N, Scarborough P, Rayner M. Cardiovascular disease in Europe 2014: epidemiological update. Europ Heart J. 2014;35(42):2950-9.

25. Stanton C, Ronsmans C, Cesarean BG. Recommendations for routine reporting on indications for cesarean delivery in developing countries. Birth. 2008;35(3):204-11.

26. Torloni MR, Betran AP, Souza JP, Widmer M, Allen T, Gulmezoglu M, et al. Classifications for cesarean section: a systematic review. PloS One. 2011;6(1):e14566.

27. Khan K, Rizvi J, Qureshi R, Mazhar R. Gestational diabetes in a developing country, experience of screening at the Aga Khan University Medical Centre, Karachi. JPMA J Pak Med Assoc. 1991;41(2):31-3.

28. Östlund I, Hanson U, Björklund A, Hjertberg R, Eva N, Nordlander E, et al. Maternal and fetal outcomes if gestational impaired glucose tolerance is not treated. Diabetes Care. 2003;26(7):2107-11.

29. Coustan DR, Imarah J. Prophylactic insulin treatment of gestational diabetes reduces the incidence of macrosomia, operative delivery, and birth trauma. Am J Obstet Gynecol. 1984;150(7):836-42.

30. Banerjee S, Ghosh U, Banerjee D. Effect of tight glycaemic control on fetal complications in diabetic pregnancies. JAPI. 2004;52:109-13.

31. Bhat M, Ramesha K, Sarma SP, Menon SSC, Kumar G. Determinants of gestational diabetes mellitus: A case control study in a district tertiary care hospital in south India. Int J Diabetes Develop Countr. 2010;30(2):91.

32. Saxena P, Tyagi S, Prakash A, Nigam A, Trivedi SS. Pregnancy outcome of women with gestational diabetes in a tertiary level hospital of north India. Indian $\mathbf{J}$ Comm Med: Offic Pub Indian Assoc Prevent Soc Med. 2011;36(2):120.

33. Mahalakshmi MM, Bhavadharini B, Kumar M, Anjana RM, Shah SS, Bridgette A, et al. Clinical profile, outcomes, and progression to type 2 diabetes among Indian women with gestational diabetes mellitus seen at a diabetes center in south India. Indian $\mathbf{J}$ Endocrinol Metabol. 2014;18(3):400.

34. Jovanovic-Peterson L. Nutritional management of the obese pregnant women. Nutr MD (USA). 1991.

35. Naylor CD. Diagnosing gestational diabetes mellitus: is the gold standard valid? Diabetes Care. 1989;12(8):565-72.

36. Nanda S, Savvidou M, Syngelaki A, Akolekar R, Nicolaides KH. Prediction of gestational diabetes mellitus by maternal factors and biomarkers at 11 to 13 weeks. Prenatal Diagnos. 2011;31(2):135-41.

Cite this article as: Priyanka. Maternal and foetal outcome in patients of gestational diabetes mellitus. Int J Reprod Contracept Obstet Gynecol 2018;7:3831-6. 